\title{
The Application Of EDI: Empirical Evidence
}

\author{
Yousef Shahwan, Canadian University of Dubai, UAE
}

\begin{abstract}
Electronic Data Interchange (EDI) is one technology that has enabled B2B E-Commerce to speak to each other electronically in order to transmit information from sender to receiver in the format the receiver wants. B2B E-Commerce is no longer synonymous with EDI (Pathak \& Baldwin, 2008). In UAE, EDI usage is in its early stage of implementation and research is highly tempted. This paper investigates the application of EDI in UAE by providing empirical evidence as to whether EDI application significantly and positively correlates to volume, cost, and profitability.
\end{abstract}

Keywords: EDI; Cost; Volume; Profitability; UAE; Business Transaction

\section{INTRODUCTION}

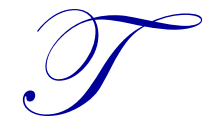

he growth of Electronic Data Interchange (EDI), as a business technology in the last decade, has greatly changed the traditions of society in which business is being conducted today. EDI has produced a revolutionary new way for businesses to communicate and interact with externals, like customers and suppliers. Investigating EDI usage in UAE and exploring challenges and opportunities surrounding EDI applications represent a continuation to previous research work that aims to cope with the higher volatility of current day systems' requirements (Shahwan, 2008). UAE companies are fast jumping into the EDI boom, and adopting such a business technology has just begun. This project investigates the usage of EDI in UAE by providing empirical evidence as to whether EDI usage correlates to volume, scale, and competitiveness. It also explores challenges surrounding the application of EDI in UAE.

Electronic-Business (E-Business) improves business performance by using electronic information technologies and opens standards to connect suppliers and customers at all steps along the value chain. E-Business encompasses three stages: E-Commerce, E-Business, and E-Partnering. E-Commerce includes the e-storefront and e-catalog, e-billing and e-payment, and rudimentary forms of e-procurement. Electronic Data Interchange (EDI) is one technology that has enabled B2B E-Commerce (parties) to speak to each other electronically in order to transmit information from sender to receiver in the format the receiver wants. B2B E-Commerce is no longer synonymous with EDI (Pathak \& Baldwin, 2008). In United Arab Emirates (UAE), history of EDI is just a decade old. In recent years, EDI is considered as one of the most exciting economic and technological trends that provides a cutting edge for businesses today. As such, more research is needed in an attempt to examine EDI applications in UAE and its competitive advantages. The idea of this research is to investigate the usage of EDI in UAE and to explore opportunities and challenges surrounding its applications.

It is clearly noted that UAE has taken responsibility for improving services in advance of computer demand. As stated earlier that EDI is just of little history in UAE, a recent initiative was taken by Dubai Port (DP) World of UAE, among other organizations, to implement advanced computer systems such as EDI (Microsoft Case Study, 2008). DP World UAE's mission is to provide secure, reliable, faster, and more efficient services for processing business transactions among all of its involved parties, including customers and governmental agencies. It was noted by DP World of UAE that adoption of EDI was to create value by vastly lowering the cost of transferring many types of information on a one-to-one, one-to-many, or many-to-many basis. Research is worthwhile to examine the uses of EDI which tends to appear in all areas of business, from customer service to governmental operations (business-type activities). UAE marketplace is in need to be checked as to whether it is just awakening to the opportunities and challenges from EDI or if more online initiatives are taken. UAE organizations 
are not lagged behind in this race and UAE is using EDI as a business technology in much the same manner as in other parts of world. However, evidence is needed to be obtained in order to prove its true potential in UAE.

In UAE, EDI usage is in its early stage of implementation and research is highly tempted. The findings of this study are expected to contribute to literature by incorporating several explanatory variables (volume, diversity, breadth, and depth) and investigating their impact on the application of EDI in UAE. It significantly adds to the literature of accounting information systems in the Gulf region as well as internationally with regard to the 'integration model' for business and accounting based on underlying assumption that effective electronic information technologies reduce costs and enhance performance (Huang et al.. 2010; Pathak \& Baldwin, 2008). Furthermore, this study's findings will contribute to a better understanding and evaluation of the benefits of EDI usage applied by UAE organizations as EDI provides a new marketplace, more opportunities to sell and market the product, and greater competitive advantages (Lianga et al., 2004). In addition, findings of this study will provide insight to UAE organizations whether capital investments in applying EDI systems will add value to organizations by vastly lowering the cost of transferring many types of information on a one-to-one, one-to-many, or many-tomany basis.

EDI usage is a complicated organizational activity that can be measured from different aspects to obtain a reliable and valid view (Liang et al., 2004). In a recent survey of supply chain practice, EDI has been reported as one of the most commonly used channels for primary communication between suppliers and customers (Holcomb et al., 2004). Although EDI adoption appears potential and promising in UAE, no research has been conducted to neither descriptively nor quantitatively measure the extent of EDI usage in UAE. Thus, this project is the first attempt to investigate the application of EDI technology by UAE organizations and to provide empirical evidence to its true potential. On the other hand, it is also the first attempt to explore opportunities and challenges to the application of EDI in UAE.

\section{LITERATURE REVIEW}

Huang et al. (2010) examined the application of information technologies, such as EDI (electronic data interchange) in reducing costs associated with order processing from both parties - the vendor and buyer. Trade credit plays an important role in financing for many businesses and industries. For the buyers, purchased inventory can be considered to be financed in whole or in part with permissible delay in payments during the purchasing process. On the other hand, both the vendor and buyer take part in order-processing cost reduction by applying EDI. Costs resulted by order-processing can also be reduced by investing in new information technologies. Huang et al. (2010) develop an integrated inventory model to determine the optimal inventory policy under conditions of orderprocessing cost reduction and permissible delay in payments. Evidence was provided that total annual variable cost function possesses some kinds of convexities. Huang et al. (2010) provide a solution procedure to determine the optimal order policy. They illustrated the solution procedure using numerical example.

Pathak \& Baldwin (2008) attempt to develop and diagnostically test measurement scales using classical measurement development framework and contemporary structural equation modeling methods. Their study is motivated by prior studies suggesting that audit resource planning in a B2B (business-to-business) e-commerce engagement is a multi dimensional construct consisting of four latent dimensions. Pathak \& Baldwin (2008) identifies candidate factors and operational dimensions of audit resource planning success within the paradigm developed by Churchill (1979). According to Pathak \& Baldwin (2008), they confirm that audit resource planning success is operationalizable as a measurement scale with the four dimensions and that such results are tools for benchmarking future efforts by audit organizations.

Lianga et al. (2004) investigate the extent of EDI usage in Beijing's hospitals along four dimensions volume, diversity, breadth, and depth. The underlying idea is that EDI usage should be assessed through examination of all four dimensions. Failure to measure a dimension may cause a skewed perception of EDI usage and the quality of the strategies based on this perception will be flawed. Results of Lianga et al. (2004) show that EDI usage is in its very early stages over their sample of 57 hospitals. They provide possible reasons for low EDI usage, such as cultural, economic, and technological reasons. 


\section{VARIABLES}

\section{Volume}

Volume is determined by the ration of the number of different business transactions that are successfully completed using EDI to the number of different business transactions that are successfully completed using communication channel other than EDI. A higher ratio implies that a firm has made progress toward the goal of productivity in transactions processing using EDI technology. Electronic business documents differ not only in business functions, but also in EDI standards. As a result, different types of EDI documents may require different EDI standards and require different hardware and software components. Therefore, more diversity is associated with higher degree of computer integration (Hart \& Saunders, 1998).

\section{Cost}

Cost is determined by the ration of processing cost per business transaction (which is deemed to be lower using EDI) over processing cost per business transaction (using a communication channel other than EDI). A lower ratio implies that a firm has made progress toward the goal of efficiency in business transactions' processing using EDI technology. To gain insight, EDI cost is measured from both the organizational and functional perspectives. Correspondingly, this study measures both the overall EDI costs and the EDI costs for specific business transactions such as purchasing, inventory, accounting, logistics, and others. Industry-specific functions, such as construction administration and interest compounding and product delivery, were also included.

\section{Profitability}

Profitability is determined by the ratio of the number of trading partners with which a firm has established using EDI to the number of trading partners with which a firm has established using a communication channel other than EDI. A higher ratio implies that a firm has made progress toward the goal of competitiveness in transactions processing using EDI technology. In this study, the percentage of manufacturers, distributors, domestic carriers, foreign carriers, IT partners, and others were obtained. The higher the percentage, the more an organization appears to be engaged in EDI and the more likely it will be successful in competing in the field of e-commerce. Cox and Ghoneim (1995) argued that a firm's competitive advantage gained from a single EDI connection in unlikely to be sustainable. An increase of EDI usage may be positively associated with the sustainability of a firm's competitive advantage in the market.

\section{THEORETICAL METHODOLOGY}

The survey data generated mostly discrete and continuous variables data. For the purpose of testing the current research hypotheses, the variables of interest, including the dependent variable, were categorical. This limits the pool of statistical techniques that may be used to predict relationships. Apart from non-parametric correlation techniques, canonical correlation analysis, probit models, and logit models may be used to examine the research hypotheses. Canonical correlation analysis is generally seen as a weaker (or last resort) statistical technique than the probit or logit models. As the current data set includes both continuous and categorical variables, this left logit model as the preferred technique for testing the research hypotheses.

The logit model is to be established by creating a dependent variable for respondents' perceptions about the values of EDI usage to business. Two options were created for the dependent variable. Under the first option, all the "high" and "very high" responses were combined into one response - "high value". Under the second option, only the "very high" responses formed the first value - "very high" - while the other responses formed the second value "other".

The choices between one of the two options available are described in terms of significant independent variables. Results of a logit analysis generate coefficients similar to a least squares regression exercise. A leastsquares regression exercise is used to generate starting values and then a bootstrapping procedure used to generate the logit model. Log-likelihood and $\chi^{2}$ statistics (for testing model significance) are also generated. 
One method used by statisticians to estimate parameters is the least squares method. The values obtained under the least squares method are called least squares estimates. In the case of categorical outcome variables (such as whether an EDI is to be used), the linear regression model is inadequate because the plot of such data appears to fall on parallel lines, each corresponding to a value of the outcome variable; say, $1=$ used and $0=$ did not use. Even if the categorical outcomes are re-conceptualized as probabilities, the predicted probabilities derived from least squares regression models can sometimes exceed the logical range of 0 to 1 . This result forms a lack of provision in the model to restrict the predicted values. Further, the $\mathrm{R}^{2}$ index derived from least squares regression for categorical outcomes does not render the usual meaning of variance explained, does not correspond to the predictive efficiency, and cannot be tested in an inferential framework (Menard, 2000).

To overcome the limitations of least squares regression, logistic regression is found superior because it 1) can accept both continuous and discrete predictors, 2) is not constrained by normality or equal variance/covariance assumptions for the residuals, and 3) is related to the discriminant function analysis through the Bayes theorem (Flury, 1997, p.558)

A typical regression model has the following general appearance:

$\breve{\mathrm{y}}=b_{0}+b_{1} \chi_{1}+b_{2} \chi_{2}+\ldots \ldots \ldots+b_{p} \chi_{p}$

where

$\breve{\mathrm{y}}=$ Estimated outcome variable value for the true $Y$

$b_{0}=$ Intercept

$b_{1} \ldots b_{p}=$ Estimated parameters corresponding to predictor values

$\chi_{1} \ldots \chi_{p}=$ Predictors' variables

Alternatively, $b_{1} \ldots b_{p}$ are called slopes, regression coefficients, or regression weights.

In the simplest case of one predictor $X$ and one discrete outcome of variable $Y$, the logistic regression model predicts the logit of $Y$ from $X$. The logit is the natural logarithm (ln) of odds of $Y=1$ (the outcome of interest). The simple logistic model has the form:

$\ln \left(\frac{P}{1-P}\right)=\log ($ odds $)=\operatorname{logit}=\alpha+\beta \chi$

Hence,

Probability $(\mathrm{Y}=$ outcome of interest $\mid X=x)=\begin{gathered}\mathrm{e}^{\alpha+\beta x} \\ 1+\mathrm{e}^{\alpha+\beta \chi}\end{gathered}$

where

$P=$ The probability of the outcome of interest or event under variable $Y$

$\alpha=$ Intercept

$\beta \mathrm{s}=$ Slope parameters

$X \mathrm{~s}=$ Set of predictors

As illustrated in equation (3), the relationship is non-linear between parameters $(\alpha, \beta)$ while the probability of observing a particular outcome for an observation, such as the application of EDI, trigged the relationship to be linear. Using the same logic as that underlying the simple logistic regression, a complex model can be constructed to improve the prediction of the logit by including several predictors. The complex logistic model is in the same form as multiple regression equations and is given as: 
$\ln \left(\frac{P}{1-P}\right)=\operatorname{logit}=\alpha+\beta_{1} \chi_{1}+\beta_{2} \chi_{2}+\beta_{3} \chi_{3}+\epsilon$

Therefore,

$$
\text { Probability }\left(\mathrm{Y}=\text { outcome of interest } \mid X 1=\chi_{1}, X_{2}=\chi_{2}, \ldots \ldots \ldots X_{\mathrm{k}}=\chi_{\mathrm{k}}\right)
$$

where

$P=$ The probability of the outcome of interest or event under variable $Y$

$\alpha=$ Intercept

$\beta \mathrm{s}=$ Slope parameters

$X_{1}=$ Number of business transactions successfully completed using EDI

$X_{2}=$ Processing cost per business transaction using EDI

$X_{3}=$ Number of trading partners established using EDI

Both the $Y$ intercept and the slope parameter are estimated by the Maximum Likelihood (ML) method. The interpretation of $\beta \mathrm{s}$ is made using either the odds ration, for categorical predictors, or the delta- $P$, for continuous predictors.

\section{RESEARCH HYPOTHESES}

In the previous sections of this paper, the research question is addressed and the development of the models is discussed. This section focuses on the models and the expected probability of occurrence. The research question addressed in this paper is whether UAE organizations, in their businesses, rate the value of EDI application in accordance to volume, cost, and profitability. To examine this question, the following hypotheses are established:

$\boldsymbol{H}_{1}$ : Whether the application of EDI will have a significant impact on the number of business transactions the organization successfully completes

$\boldsymbol{H}_{2}$ : Whether the application of EDI will have a significant impact on the processing cost per business transaction that the organization incurs

$\boldsymbol{H}_{3}$ : Whether the application of EDI will have a significant impact on the number of trading partners the organization links

The null hypothesis states that all $\beta$ s equal zero. A rejection of this null hypothesis implies that at least one $\beta$ does not equal zero in the population.

\section{The Sample}

Dubai was chosen as the research site for several reasons. First, it is the economic capital of United Arab Emirates and one of the UAE's most industrialized cities. Second, many organizations in Dubai have excellent IT infrastructures in place. Third, Dubai is one of the seven emirates that established EDI centers of the Gulf Electronic Data Interchange business network early 1996. Due to these factors, organizations in Dubai usually receive more assistance from the government and various industry organizations to implement new technologies than organizations in other emirates. As a result, Dubai World organizations are typically the earliest organizations to experiment with new technologies. Therefore, choosing Dubai as the research site means that our findings might predict the future of EDI usage in organizations in other parts of Dubai. The strategies generated based on our findings will help Dubai promote and implement EDI in organizations not only in Dubai, but also nationwide. 


\section{METHODOLOGY}

The purpose of this proposal is to investigate the application of EDI in UAE and to explore opportunities and challenges surrounding its applications. To do so, a survey questionnaire will be developed based on dimensions of EDI application. These dimensions of EDI application include three variables - volume, cost, and profitability. The theoretical model of this proposal is based on EDI application dimensions, which was previously used by (Hart \& Saunders, 1998). The model is to investigate the application of EDI in UAE and to provide empirical evidence as whether EDI should be adopted. Accordingly, this study calls for the following two research questions:

1. Should UAE apply EDI as an electronic information technology when processing business-type transactions? If so, then how does EDI usage correlate to volume, cost, and profitability?

2. What are the opportunities and challenges surrounding EDI applications in UAE?

Logit and Probit estimation models, among other statistical techniques, will be used to deal with data obtained from the survey questionnaire.

\section{RESULTS}

Among the respondents, three types of EDI connections have been identified - internal EDI, regional EDI, and international EDI. Internal EDI is intra-organizational document exchange at the departmental level. Regional EDI refers to inter-organizational document exchange in the organizational level but is restricted within a certain geographical area. In Dubai, EDI services are provided by the government's EDI centers located in major cities at the regional, national, and international levels.

\section{Volume}

As shown in Table 1, the average overall EDI volume is 58.25, which means that, on average, more than half of organization documents are exchanged via EDI between departments of the organizations or between the organizations and their trading partners. For the various specific functions, including purchasing, inventory, accounting, compounding, finance, IT, and logistic, the EDI volume ranges from $47.75 \%$ to $53.25 \%$. The KruskalWallis test (Hollander \& Wolfe, 1973; Neter et al., 1996) - a non-parametric alternative of ANOVA - was used to examine the different EDI volumes among different organizations' levels. Results indicated that the EDI volumes in purchasing are significantly different among organization types $\left(\chi^{2}=6.16, p<0.05\right)$. Further analyses using MannWhitney tests (Hollander \& Wolfe, 1973; Neter et al., 1996) - a non-parametric alternative of $t$-test - pinpointed that internal and international levels of organizations' connections are significantly different in EDI volume for purchasing $(U-24.00, p<0.05)$ and IT $(U=25.50, p<0.05)$. There are no significant differences among the three types of organizations' connections in terms of other EDI volumes.

Table 1: EDI - Volume

\begin{tabular}{|l|c|c|c|c|}
\hline & Internal & Regional & International & Mean (\%) \\
\hline Accounting & 79.00 & 80.50 & 84.00 & 83.00 \\
\hline Inventory & 89.00 & 80.00 & 82.50 & 81.25 \\
\hline Compounding & 95.00 & 91.50 & 77.25 & 73.50 \\
\hline Finance & 57.00 & 60.00 & 69.00 & 66.25 \\
\hline IT & 8.00 & 25.50 & 58.50 & 50.50 \\
\hline Purchasing & 0.00 & 4.00 & 22.25 & 26.00 \\
\hline Logistics & 3.50 & 12.50 & 23.25 & 21.25 \\
\hline Overall & 55.25 & 50.57 & 59.54 & 58.25 \\
\hline
\end{tabular}

\section{Cost}

As indicated in Table 2, the average number of different EDI document types is $59.71 \%$ at the international level, $55.29 \%$ at the regional level, and $51.57 \%$ at the internal level. The most mentioned document types include accounting forms, delivery charts, inventory quotes, compounding files, and billing forms. The Kruskal-Wallis test shows the EDI diversity does not differ significantly among the three levels of organizations $\left(\chi^{2}=4.22, p>0.05\right)$. 
Table 2: EDI - Cost

\begin{tabular}{|l|c|c|c|c|}
\hline & Internal & Regional & International & Mean (\%) \\
\hline Accounting & 81.00 & 82.00 & 87.50 & 83.50 \\
\hline Inventory & 87.50 & 79.25 & 82.50 & 82.00 \\
\hline Compounding & 94.50 & 93.00 & 74.00 & 75.25 \\
\hline Finance & 55.00 & 61.75 & 70.75 & 67.00 \\
\hline IT & 29.00 & 27.25 & 58.50 & 51.50 \\
\hline Purchasing & 0.00 & 26.75 & 23.00 & 25.25 \\
\hline Logistics & 14.00 & 17.00 & 21.75 & 23.75 \\
\hline Overall & 51.57 & 55.29 & 59.71 & 56.75 \\
\hline
\end{tabular}

\section{Profitability}

Table 3 shows the EDI breadth of the organizations. It is most likely for an organization to have an EDI connection with its distributor partners (83\%) and least likely with its foreign carrier partners (25\%). The KruskalWallis test indicated that none of the EDI breadth is significantly different among the three levels of organizations $(p>0.05)$.

Table 3: EDI - Profitability

\begin{tabular}{|l|c|c|c|c|}
\hline & Internal & Regional & International & Mean (\%) \\
\hline Distributor & 86.00 & 79.50 & 86.25 & 83.00 \\
\hline IT & 85.00 & 72.50 & 81.75 & 80.75 \\
\hline Bank & 83.00 & 74.75 & 76.25 & 77.25 \\
\hline Manufacturer & 60.00 & 61.25 & 67.25 & 66.75 \\
\hline Domestic carrier & 7.50 & 46.25 & 57.75 & 52.75 \\
\hline Foreign carrier & 0.00 & 24.25 & 28.75 & 25.00 \\
\hline
\end{tabular}

\section{CONCLUSION}

The EDI industry in UAE has come a long way since its early days. More than five years ago, ISPs just took off. There was no usage, no broadband, no content, and no perfect laws for regulating EDI transactions. Not only UAE customers, but also UAE business organizations, were unaware of the advantages of transactions made though EDI. However, now the picture has totally changed. It becomes evident that EDI offers huge opportunities and today's Internet has become a part of our daily lives. UAE organizations are also realizing the potential of EDI and using EDI technologies in their day-to-day business operations. Now the UAE market has matured and new market players have entered the market space.

In UAE, companies from various segments have actively prompted Internet usage and EDI application. Per the empirical results, the application of EDI is found significantly and positively correlated to the number of business transactions that the organizations successfully complete. It was also found that the application of EDI is significantly and positively correlated to the processing cost per business transaction that organizations incur. In addition, it was also found that the application of EDI is significantly and positively correlated to the number of trading partners that organizations have. Overall, it can be concluded that the application of EDI is significantly and positively correlated to volume, cost, and profitability. At the same time, end users are also forcing vendors to expand their operating services and urging organizations to adopt new IT business models such as EDI e-business modeling.

\section{AUTHOR INFORMATION}

Dr. Yousef Shahwan is an Associate Professor of Accounting at Canadian University of Dubai in United Arab Emirates. He received his PhD in Accounting from University of Western Sydney in Australia and MBAcc from Aberdeen University in UK. He published many articles in international journals and participated in many international accounting and business conferences worldwide. Dr. Shahwan's research area of interest is in the field of financial reporting and accounting regulations. E-mail: yousef@cud.ac.ae 


\section{REFERENCES}

1. Churchill, G. A. (1979). A Paradigm for Developing Better Measures of Marketing Constructs. Journal of Marketing Research, 16(4: November), p64-73.

2. Cox, B., \& Ghoneim, S. (1995). Implementing a national EDI service: issues in developing countries \& lesson from the UK. Paper presented at the International Federation for Information Processing.

3. Flury, B. (1997). A First Course in Multivariate Statistics. New York: Springer.

4. Gibbs, J., Kraemer, K. L., \& Dedrick, J. (2003). Environment and policy factors shaping global ecommerce diffusion: a cross-country comparison. Information Society, 19(1), 5.

5. Gunasekaran, A., McGaughey, R. E., Ngai, E. W. T., Rai, B. K. (2009). E-Procurement adoption in the Southcoast SMEs. International Journal of Production Economics, Nov2009, Vol. 122, Issue 1, p161-175.

6. Hart, P. J., \& Saunders, C. S. (1998). Emerging electronic partnerships: antecedents and dimensions of EDI use from the supplier's perspective. Journal of Management Information Systems, 14(4), p87-112.

7. Holcomb, M., Fungate, B., Moore, P., Ross, T., \& Quinn, F. (2004). Connectivity in the supply chain. Tech. Rep., 2004.

8. Huang, Chao-Kuei; Tsai, Deng-Maw; Wu, Ji-Cheng; Chung, Kun-Jen (2010). An integrated vendor-buyer inventory model with order-processing cost reduction and permissible delay in payments. European Journal of Operational Research, Vol. 202 Issue 2, p473-478.

9. Huff, A. (2009). The New Face of EDI. Commercial Carrier Journal, Vol. 166, Issue 12, p54-57.

10. Johnson, D., Allen, B., \& Crum, M. (1992). The state of EDI usage in the motor carrier industry. Journal of Business Logistics, 13(2), p111-142.

11. Jun, M., Cai, S., \& Peterson, R. (2000). EDI use and participation models: from the inter-organizational relationship perspective. Industrial Management and Data Systems, 100(9), p412-420.

12. Juul, N., Andersen, K., \& Bjorn-Andersen, N. (1998). Electronic Commerce in Denmark: The Spread of EDI in B-2-B Transactions. $3^{\text {rd }}$ USENIX workshop on Electronic Commerce. Boston, Massachusetts, August 31 - September 3.

13. Lianga, H., Yajiong Xueb, Terry Anthony Byrdc, R. Kelly Rainer Jr. (2004). Electronic data interchange usage in China's healthcare organizations: the case of Beijing's hospitals. International Journal of Information Management 24, p507-522.

14. Massetti, B., \& Zmud, R. (1996). Measuring the extent of EDI usage in complex organizations: strategies and illustrative examples. MIS Quarterly, 20(3), p331-345.

15. Menard, S. (2000). Coefficients of determination for multiple logistic regression analysis. The American Statistician 54(1): p17-24.

16. Microsoft Case Studies (2008). Ports Company Navigates Business Process Challenges with Microsoft Office SharePoint Server 2007 and InfoPath 2007. DP World, August 262008 (http://www.microsoft.com/caseStudies/Case_Study_Detail.aspx?casestudyid=4000002583).

17. Pathak, J., \& Baldwin, A. (2008). Audit Resource Planning Success in B2B E-Commerce: Development and Testing of a Measurement Scale. Information Systems Management, Summer2008, Vol. 25 Issue 3, p230-243.

18. Shahwan, Y. (2008). Methods of Teaching to the Course of Accounting Information Systems: Factors of Preference. Review of Business Information Systems, RBIS, Volume 12, Number 1, pp.103-112. 